Article

\title{
Olive Mill Wastewater: From a Pollutant to Green Fuels, Agricultural Water Source, and Bio-Fertilizer. Part 2: Water Recovery
}

\author{
Patrick Dutournié $^{1}$, Mejdi Jeguirim ${ }^{1, *} \mathbb{C}$, Besma Khiari ${ }^{2}\left(\mathbb{D}\right.$, Mary-Lorène Goddard ${ }^{3,4}(\mathbb{D}$ and \\ Salah Jellali ${ }^{5}$ (i) \\ 1 CNRS ISM2 UMR 7361, Université de Haute Alsace, Université de Strasbourg, 68093 Mulhouse, France; \\ Patrick.dutournie@uha.fr \\ 2 National School of Engineers of Carthage, 45 rue des entrepreneurs, Charguia 2-1002, 2035 Tunis, Tunisia; \\ besmakhiari@yahoo.com \\ 3 CNRS, LIMA UMR 7042, Université de Haute-Alsace, Université de Strasbourg, 68093 Mulhouse, France; \\ mary-lorene.goddard@uha.fr \\ 4 LVBE, EA 3991, Université de Haute-Alsace, 68008 Colmar, France \\ 5 Wastewaters and Environment Laboratory, Water research and Technologies Centre, 8020 Soliman, Tunisia; \\ salah.jallali@certe.rnrt.tn \\ * Correspondence: mejdi.jeguirim@uha.fr; Tel.: +33-389-6729
}

Received: 20 March 2019; Accepted: 10 April 2019; Published: 13 April 2019

\begin{abstract}
Water shortage is a very concerning issue in the Mediterranean region, menacing the viability of the agriculture sector and in some countries, population wellbeing. At the same time, liquid effluent volumes generated from agro-food industries in general and olive oil industry in particular, are quite huge. Thus, the main aim of this work is to suggest a sustainable solution for the management of olive mill wastewaters (OMWW) with possible reuse in irrigation. This work is a part of a series of papers valorizing all the outputs of a three-phase system of oil mills. It deals with recovery, by condensation, of water from both OMWW and OMWW-impregnated biomasses (sawdust and wood chips), during a convective drying operation (air velocity: $1 \mathrm{~m} / \mathrm{s}$ and air temperature: $50^{\circ} \mathrm{C}$ ). The experimental results showed that the water yield recovery reaches about $95 \%$. The condensate waters have low electrical conductivity and salinities but also acidic $\mathrm{pH}$ values and slightly high chemical oxygen demand (COD) values. However, they could be returned suitable for reuse in agriculture after additional low-cost treatment.
\end{abstract}

Keywords: OMWW; drying; water recovery; water characterization; sustainable development

\section{Introduction}

Water scarcity in the Mediterranean region is becoming a growing concern, menacing the viability of agriculture, which represents an important economic sector in many countries [1]. This water shortage is accentuated in the last decades due to the undeniable climate change causing recurrent long periods of drought. The efficient wastewaters treatment and their controlled reuse in irrigation can contribute to water saving and potentially address this water shortage issue [2,3].

Generally, treated municipal wastewater is the main recyclable source for irrigation. This treatment and reuse process contributes strongly to the potable water resources conservation and reduces the wastewater's negative impacts related to the effluents release into the environment [4]. However, the wastewater chemical composition needs to be controlled due to the presence of a variety of pollutants including heavy metals, organic compounds, bacteria, etc. $[5,6]$. These contaminants may generate problems for agricultural production affecting crop quantity and quality $[7,8]$. Therefore, the 
interest turned towards agro-industrial wastewaters, because of the large amounts produced and their relative high contents in nutrients [9].

Still, in the Mediterranean region, the olive oil industry generates large quantities of olive byproducts that should be appropriately managed [10]. Different kinds of extraction processes are commonly used. The three-phase system, mainly used in Tunisia, Greece, and Italy, generates a solid residue (named olive mill solid waste (OMSW)) and a liquid effluent (olive mill wastewater $(\mathrm{OMWW})$ ). Approximately, 30 million tons of OMWW are generated each year in the Mediterranean region [11]. The OMWW, which is slightly acidic, contains a large fraction of water (around 80\%) and high contents of soluble organic compounds and salts [12]. These wastes are often discharged and stored in natural open-air basins (Figure 1a). Indeed, the OMWW surface rapidly dries (as a result of the heat supplied by air flow and sun heating) and a crust (with a plastic consistency) rapidly covers the surface (Figure $1 b-d$ ). Such crust inhibits the mass and heat transfers and, therefore, water evaporation. In these conditions, the aqueous phase could diffuse and percolate in the subsoil, leading to soils infertility and groundwater pollution. Furthermore, it is the origin of bad smells and the development of several varieties of mosquitoes.

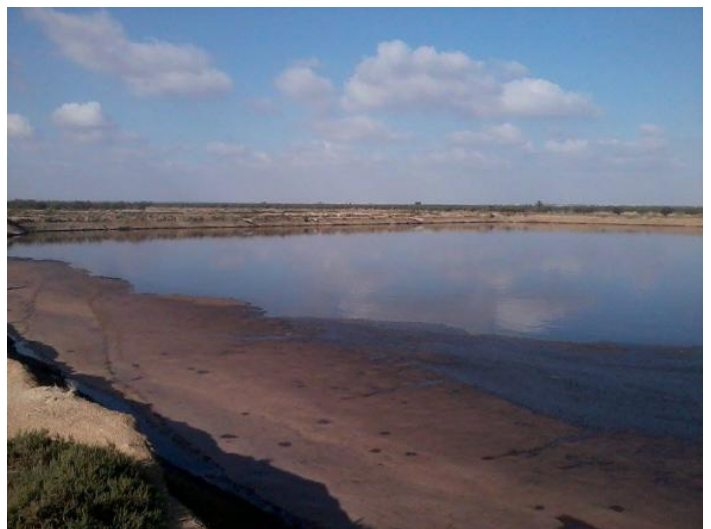

(a)

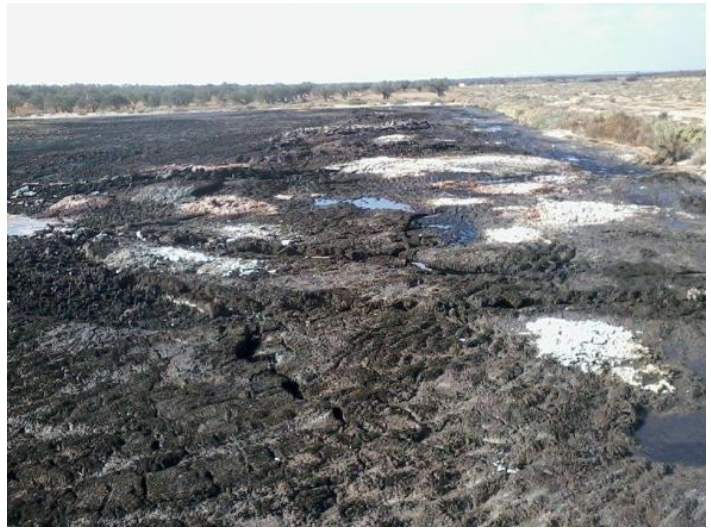

(c)

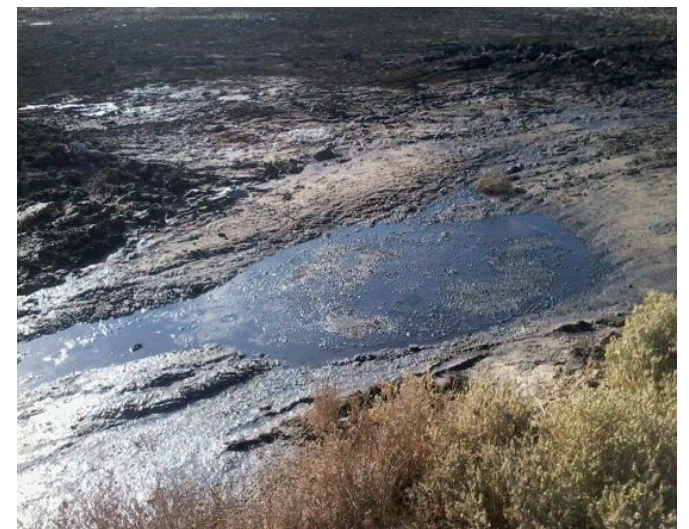

(b)

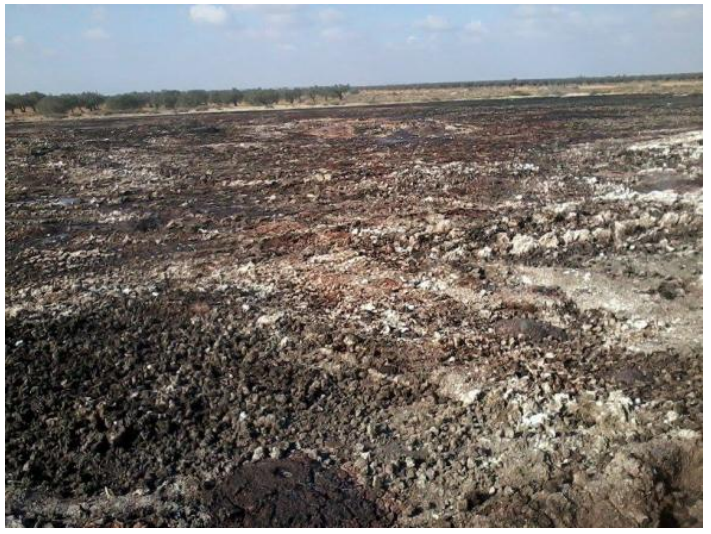

(d)

Figure 1. Photos of olive mill wastewaters (OMWW) evolution in deposit basins in the region of Mahdia (Tunisia) at different drying stage.

Sustainable OMWW management has been pointed out as an urgent challenge in order to tackle the disadvantages cited above [11-13]. More than 20 applicable procedures are mentioned in scientific publications, including elemental operations such as flocculation, ultrafiltration, and chemical treatments or combined operations such as centrifugation-ultrafiltration. These techniques are generally tested in a laboratory or in a pilot plant, without posterior industrial projections. Some treatment and valorization systems presenting some degree of applicability are summarized in Table 1. 
Table 1. Main applied technologies for OMWW treatment.

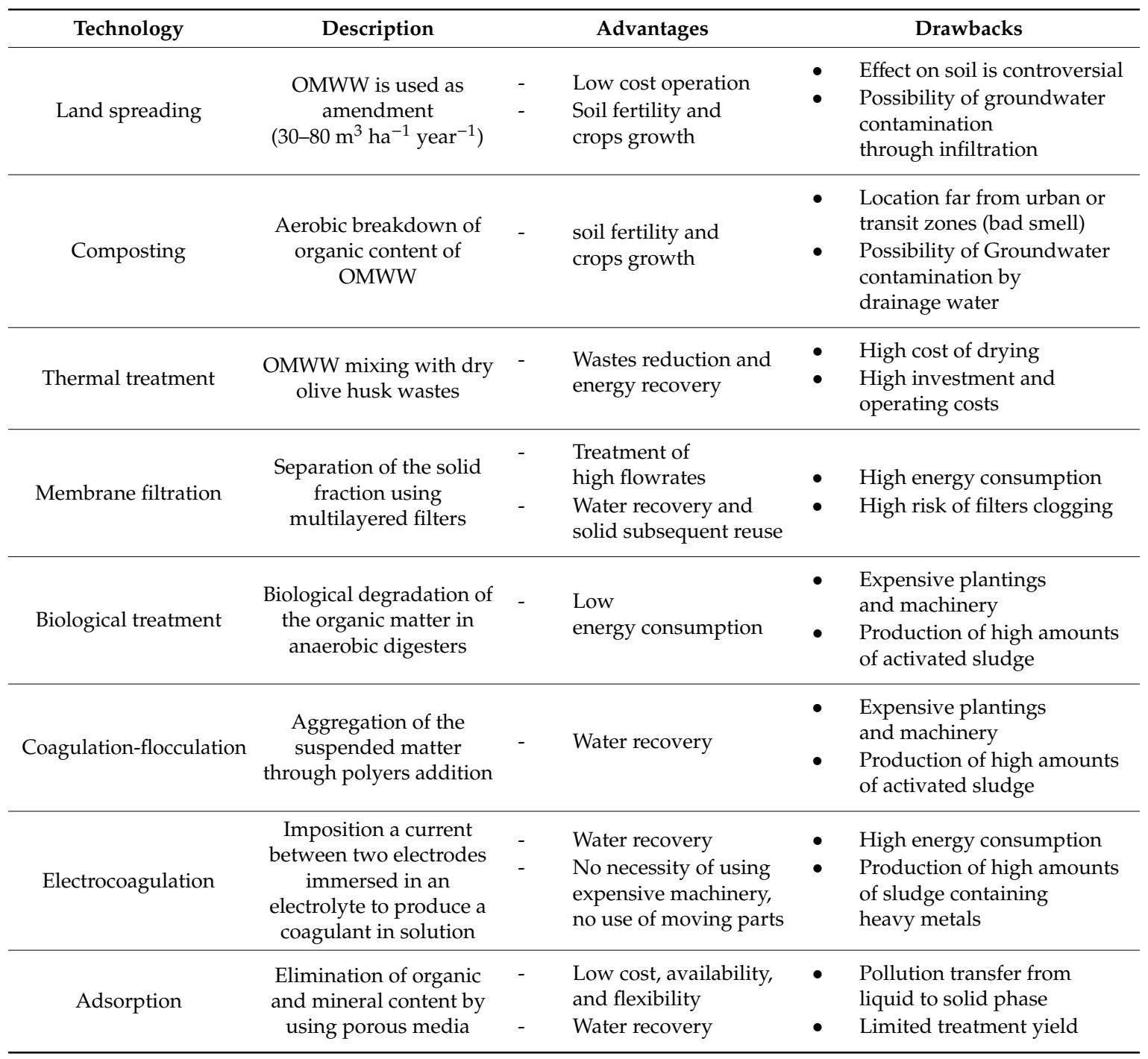

The agronomic use of OMWW through its spreading on soils, directly or following a composting process, has several drawbacks, including the modification of soils' physical, chemical, and biological properties. On the contrary, the thermal treatment could be an interesting solution since it permits the recovery of biofuels (for energy production) and biochars (for agronomic and environmental purposes). However, the high moisture content is not economically favorable for the direct OMWW thermochemical conversion [14,15]. In order to face such constraint, the OMWW impregnation on lignocellulosic biomass was proposed to recuperate the organic matter followed by agropellets production [16]. Nevertheless, the pellets' combustion in domestic boilers has some drawbacks, like particulate matters emissions and ash accumulation, due to the high mineral contents in OMWW [17].

Recently, an environmentally friendly strategy for the OMWW valorization, including different procedures, was implemented [18]. The first step was the impregnation of wood sawdust with OMWW, leading to the recovery of the OMWW's organic and nutrient compounds. The second step of drying showed that the impregnation stage led, not only to the oily fraction retention, but also to the acceleration of water evaporation kinetic. The third step consisted of the pyrolysis of these impregnated samples, which led to high yields of chars with attractive nutrients concentrations, especially potassium and phosphorus. The last step concerned the application of the obtained chars as bio-fertilizers. This operation confirmed a beneficial effect on the plant growth [18]. 
More precisely, and as far as the drying step is concerned, the experiments were carried out in a convective dryer under different operating conditions (velocity, temperature). The kinetic results confirmed that the drying of the impregnated samples was faster than that of OMWW samples. But more importantly, such procedure could probably allow an ecologic recovery of water from OMWW [19]. In this vein, this paper aims to examine the water recovery from the drying step and its characterization for a possible reuse in irrigation. Indeed, water management will be increasingly strategic, especially in the Mediterranean basin. Very few works in the literature deal with the recovery of water for an agricultural purpose after a drying operation [20]. These studies are focused on the recovering of added-value chemicals in water, for example, essential oils extraction [21].

\section{Materials and Methods}

\subsection{Samples Preparation}

Olive mill wastewater (OMWW) used in this study was provided by an olive mill located in the city of Touta, North East of Tunisia. This olive mill plant uses the three-phase extraction system for olive oil production. Sawdust was provided by Nollinger sawmill located in Illfurth (France). Wood chips were supplied by the firewood supplier Farmingroad located in Reguisheim (France).

Five samples were prepared during this investigation in order to examine the water recovery process and analyze its quality for the possible reuse in agriculture. The raw OMWW sample (moisture content: $91 \%$ wet basis, wb.) was used for the impregnation procedure. This sample was also used without impregnation for the water recovery tests. The impregnation samples were prepared according to the procedure applied in previous investigations $[16,17]$. Impregnated sawdust (IS) was prepared by mixing $2 \mathrm{~kg}$ of OMWW with $0.5 \mathrm{~kg}$ of sawdust (moisture content: $24 \% \mathrm{wb}$.) for $24 \mathrm{~h}$. The initial moisture content of the IS before drying was $78 \%$ wb. In a similar way, impregnated wood chips (IWC) were prepared by mixing $1.5 \mathrm{~kg}$ of OMWW with $0.5 \mathrm{~kg}$ of wood chips (moisture content: $24 \% \mathrm{wb}$.). The initial moisture of IWC before the drying test was $74 \% \mathrm{wb}$.

Two complementary samples (blank tests) were required in order to identify the effect of the OMWW impregnation on the water quality. Hence, humidified sawdust (HS) was prepared by emerging $0.5 \mathrm{~kg}$ of sawdust in $2 \mathrm{~L}$ deionized water respecting the same procedure as for OMWW impregnation. Humidified wood chips (HWC) were prepared by emerging $0.5 \mathrm{~kg}$ of wood chips in $1.5 \mathrm{~L}$ deionized water.

\subsection{Experimental Drying Tests}

Experimental drying tests were performed using a laboratory convective dryer (Figure 2) previously described in details [19].

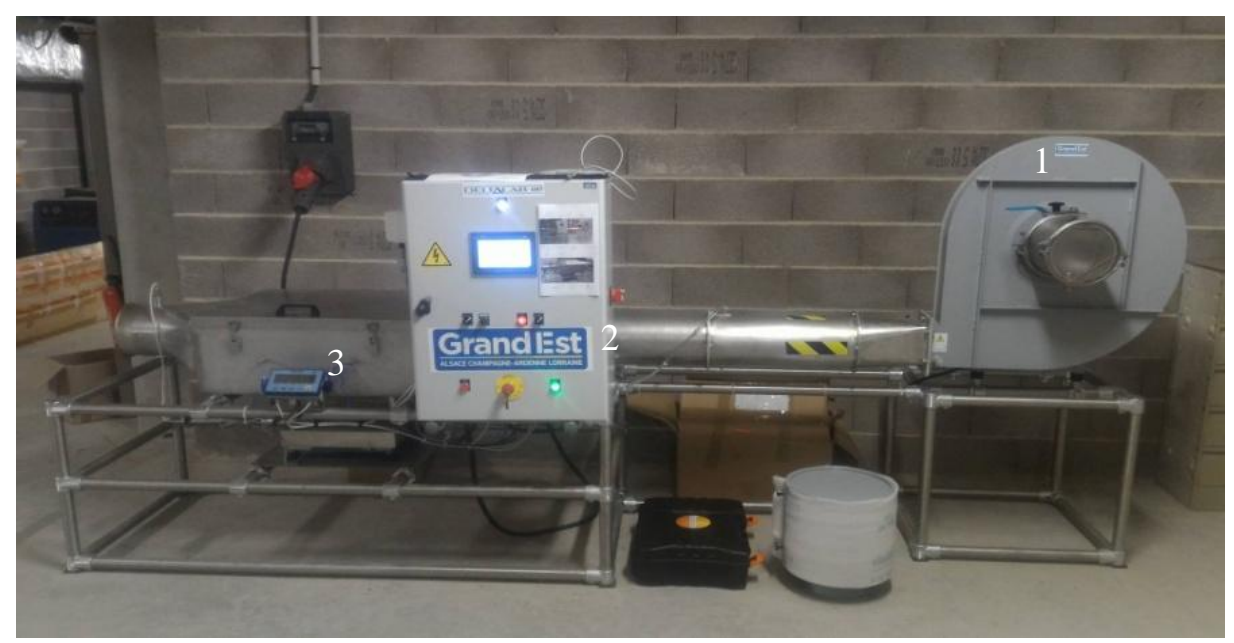

Figure 2. Experimental dryer. 
During the drying tests, samples were placed in an open Plexiglas box $(19 \times 13 \times 3 \mathrm{~cm})$. The level of wet samples is accurately adjusted to the upper rim of the box. The mass of the studied sample was recorded in order to measure the moisture content progress versus time. A fan (1) introduces air in the dryer with an air velocity of $1 \mathrm{~m} / \mathrm{s}$. The fan is settled for having an air velocity directly onto the material surface. The air heating is achieved by electrical resistances (2) at $50{ }^{\circ} \mathrm{C}$. The air temperature in the drying chamber is controlled by a proportional-integral-derivative (PID) control loop. The operating drying conditions $\left(1 \mathrm{~m} / \mathrm{s}\right.$ and $\left.\mathrm{T}=50{ }^{\circ} \mathrm{C}\right)$ were selected from previous results [19] in order to have a good compromise between the drying time and the energy consumption. Temperature, humidity, and flow rate are continuously measured by several sensors; 1 for fluid velocity in the duct, 3 humidity sensors (room air, hot air at the drying chamber inlet, and at the dryer outlet) and 7 thermocouples (room air, hot air, 4 in the drying chamber, and 1 at the dryer outlet).

From mass measurements, the moisture content $\mathrm{X}$ is given by:

$$
X(t)=\frac{m(t)-m_{f}}{m(t)}
$$

where $\mathrm{m}(\mathrm{t})$ is the sample weight at time $\mathrm{t}$ and $\mathrm{m}_{\mathrm{f}}$ is the sample weight at the end of the drying.

\subsection{Water Condensation and Recovery}

In order to examine the water recovery from the impregnated samples, an accessory material was implemented at the dryer outlet. In particular, a boiler condenser (Figure 3) was used for the water condensation at the outlet of the dryer. For this purpose, the moist air flow is introduced in the boiler exchanger. The latter is cooled by an antifreeze fluid circulating into the aluminum jacket.

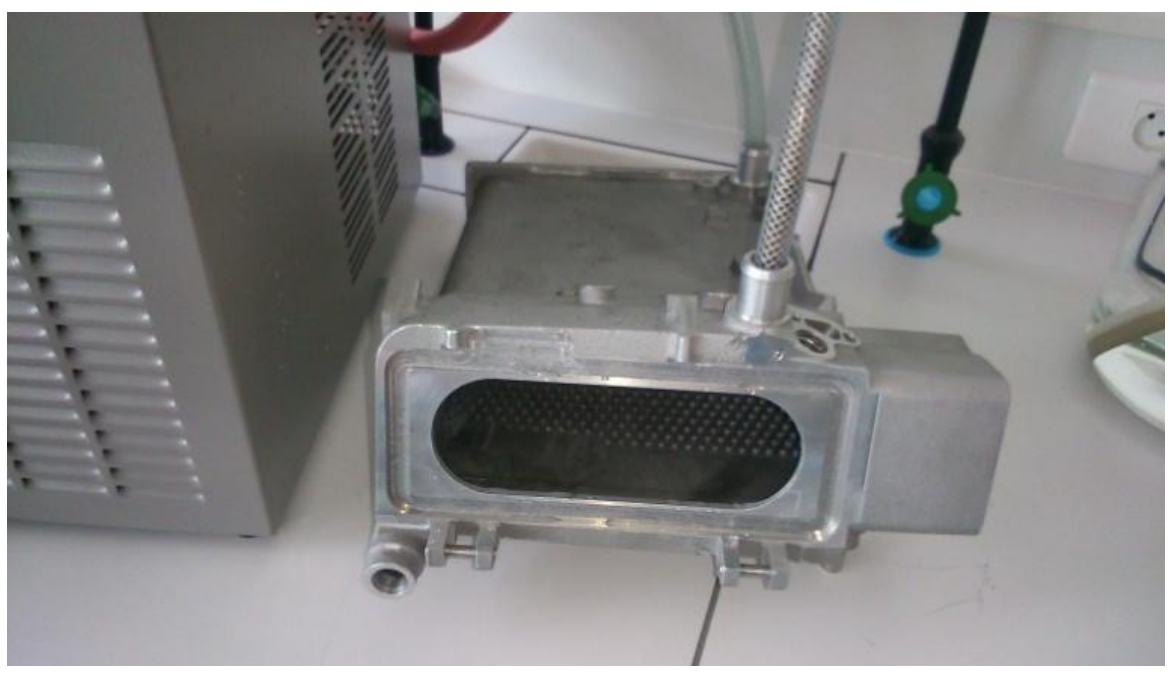

Figure 3. Boiler condenser used for the water recovery experiments.

\subsection{Condensed Water Characterization}

The condensed water recovered after the drying operation of raw OMWW, IS, IWC, HS, and HWC was physico-chemically characterized by using different analytical techniques in order to assess their potential reuse for irrigation in agriculture. This characterization concerned the assessment of: (i) Their pH by using a HI 2211 (HANNA Instrument, Lingolsheim, France) apparatus, (ii) their electrical conductivity (salinity) through a PC 5000 L (VWR, Radnor, PA, USA) device, (iii) their chemical oxygen demand (COD) via the open reflux using dichromate titrimetric method [22], and (iv) their contents in inorganic anions and cations through ion chromatography analyzer (Metrohm, Herisau, Switzerland). 


\subsection{Gas Chromatography-Mass Spectrometry}

\subsubsection{Chemicals and Reagents}

Reagents were purchased from Sigma-Aldrich (St Quentin Fallavier, France) for methoxyamine hydrochloride and Alfa Aesar (by Thermo Fisher, Karlsruhe, Germany) for anhydrous pyridine and MSTFA). LC-MS grade water was purchased from Fisher Scientific (Illkirch, France).

\subsubsection{Derivatization}

A volume of $30 \mu \mathrm{L}$ of each sample was lyophilized and then re-dissolved in $20 \mu \mathrm{L}$ of $30 \mathrm{mg} \mathrm{mL}^{-1}$ methoxyamine hydrochloride in anhydrous pyridine and derivatized at $37^{\circ} \mathrm{C}$ for 120 min with mixing at $600 \mathrm{rpm}$. The samples were incubated for $30 \mathrm{~min}$ with mixing at $600 \mathrm{rpm}$ after addition of both $80 \mu \mathrm{L}$ of N-methyl-N-(trimethylsilyl)trifluoroacetamide (MSTFA). Each derivatized sample was allowed to rest for $30 \mathrm{~min}$ prior to injection.

\subsubsection{GC-MS Instrument Conditions}

Samples $(1 \mu \mathrm{L})$ were injected into a GC-EI-MS system comprising an AOC-20i Auto-injector, a Shimadzu GC-2010 gas chromatograph, and a Shimadzu GCMS-QP2010 mass spectrometer (Shimadzu, Kyoto, Japan) with an electron impact (EI) ion source and quadrupole analyzer. The GC was operated in constant linear velocity mode $\left(40.3 \mathrm{~cm} \mathrm{~s}^{-1}\right)$ with helium as the carrier gas and using phenoxyacetic acid as a standard for retention time locking of the method. The MS was adjusted using perfluorotributylamine (PFTBA). An SGE Analytical Science BPX5 column ( $25 \mathrm{~m}$ long, $0.15 \mathrm{~mm}$ inner diameter, $0.25 \mu \mathrm{m}$ film thickness) was used. The injection temperature in splitless mode was set at $310^{\circ} \mathrm{C}$, the MS transfer line at $330^{\circ} \mathrm{C}$, and the ion source adjusted to $200^{\circ} \mathrm{C}$. Helium was used as the carrier gas at a flow rate of $0.97 \mathrm{~mL} \mathrm{~min}{ }^{-1}$. The following temperature program was used; injection at $110^{\circ} \mathrm{C}$, hold for $4 \mathrm{~min}$, followed by a $10.5^{\circ} \mathrm{C} \mathrm{min}{ }^{-1}$ oven temperature, ramp to $155^{\circ} \mathrm{C}$, then $11.5^{\circ} \mathrm{C} \mathrm{min}^{-1}$ oven temperature, ramp to $350{ }^{\circ} \mathrm{C}$, and a final 6 min heating at $350{ }^{\circ} \mathrm{C}$.

\subsubsection{Chemical Identification}

Gas Chromatography-Mass Spectrometry (GC-MS) results are analyzed from the National Institute of Standards and Technology (NIST) 05 database and identified chemicals are validated by comparison with injection of commercial standards.

\section{Results}

\subsection{Kinetic Study}

Figure 4 shows the evolution of the drying in time of the OMWW, IS, and IWC in terms of moisture content $\mathrm{X}$ versus time.

One can see that for the three samples, the moisture ratio decreased continuously with the drying time, with different constant rate drying period. This is in accordance with other works dealing with the drying of OMWW [23] and of other biomasses impregnated with OWWW [19,23].

During the first phase of drying, the slope of the moisture curve was very dependent on the sample used. Indeed, the highest one was observed for the IWC, followed by IS, and OMWW. As this stage corresponded to the departure of free or/and weakly bound water, one can attribute the difference to the mixture density and its porosity. Indeed, there were more voids within the impregnated wood chips (IWC), which led to a better air infiltration, whereas the impregnated sawdust (IS) was more compact and formed a paste-like mixture. As for the OMWW, the oily layer transformed into a crust at the top of the liquid, which may explain the slow evaporation rate and why the first stage ended earlier (16 h) compared to IWC (19.5 h) and IS (33.8 h).

In the second drying stage (drying stage separation shown by a dotted line in Figure 3), this tendency was inversed and the slopes were in the following order: OMWW > IS > IWC. 
The acceleration in OMWW drying, during the second phase, could be the result of the cracking of the crust layer (white patch shown in Figure 5, circled in red), due to the evaporated water under the crust forcing a way out on one hand and to the mechanical action of the convective air on the other hand. The resulting fissures then allow water to escape, and therefore the drying rate is increased.

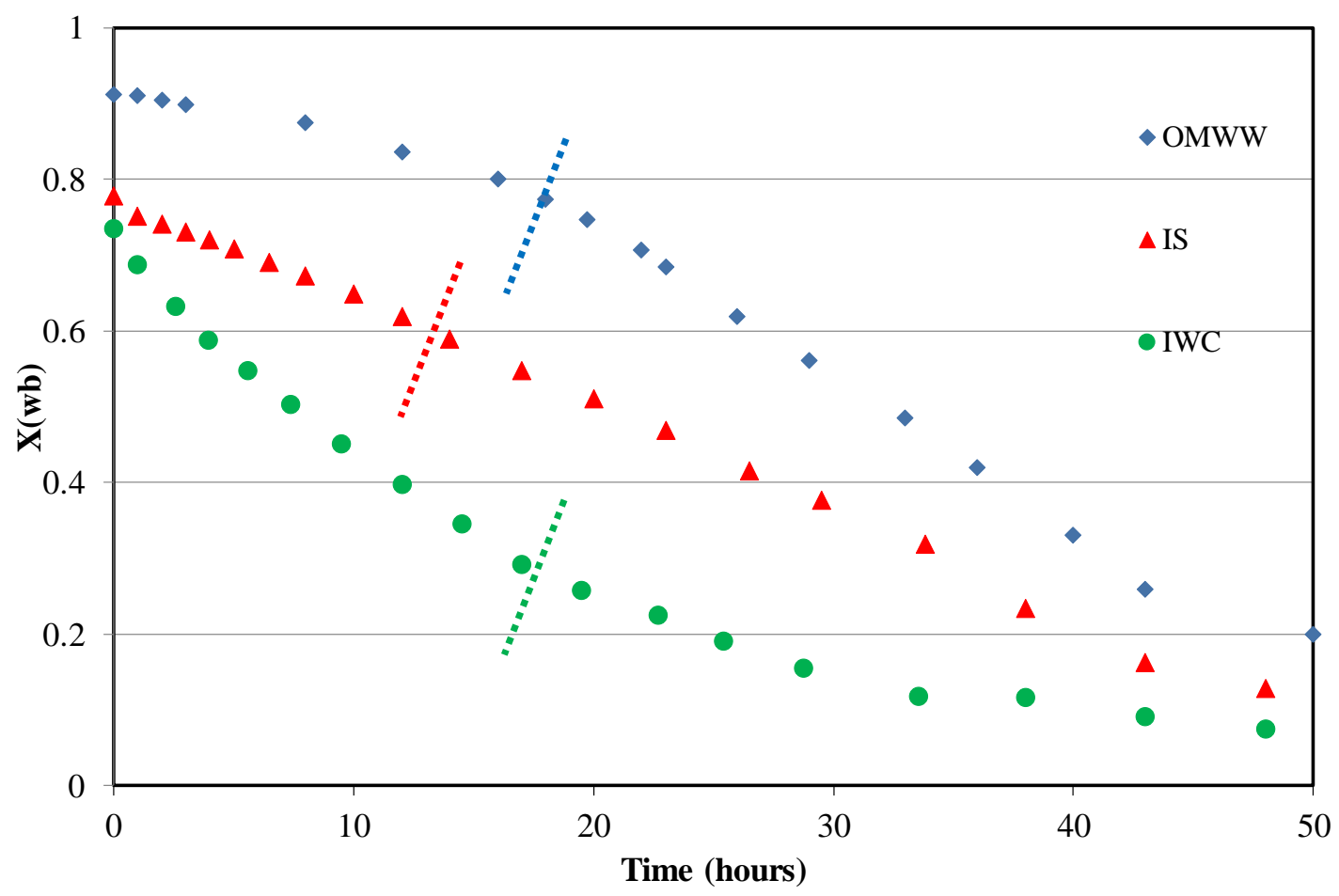

Figure 4. Moisture content profile during the convective drying for raw olive mill wastewater (OMWW), impregnated sawdust (IS), and impregnated wood chips (IWC).

The reason the IS drying rate was higher than that of IWC during the second stage may be related to the impregnation procedure and the material nature. Indeed, as sawdust is a finer and thinner material than the wood chips, its mixture with the oily liquid might have promoted the formation of stronger chemical bonds between the solid matrix and the liquid phase. The phenomenon of water and oil retention on the biomass fibers is probably the reason their slopes were inferior.

For the two impregnated solids, the water loss rate was less in the second stage, compared to the first one. Following the decrease in the concentration gradient between the samples and the surrounding air, mass flow was limited within the solid samples. This is due to bound water, which is more difficult to remove. In fact, the drying process is limited by a diffusion phase within the solid matrix. The vaporization front gradually moves towards the interior of the material. As water vapor has a longer way to cross, the surface pressure decreases. The difference between the latter and the vapor pressure of the surrounding air also decrease, slowing down the exchange and consequently the rate of drying [24].

Finally, it is important to point out that the drying of the impregnated biomasses was faster than that of the OMWW sample $(\times 2$ for IS and $\times 3.5$ for IWC) during only the first stage of drying. Such a conclusion was reached for impregnated olive cake and impregnated sawdust (two times faster than OMWW for both materials) but for the whole operation of drying [19]. This may be linked to the fact that in the mentioned paper, the layer to dry was thin $(3 \mathrm{~mm})$ whereas it was $3 \mathrm{~cm}$ in the present study. During the second stage, the drying was lower $(\times 1 / 2$ for IS and $\times 1 / 3.5$ for IWC $)$ compared to OMWW, which explains why the amount of water evaporated per hour was substantially the same for all the samples. 

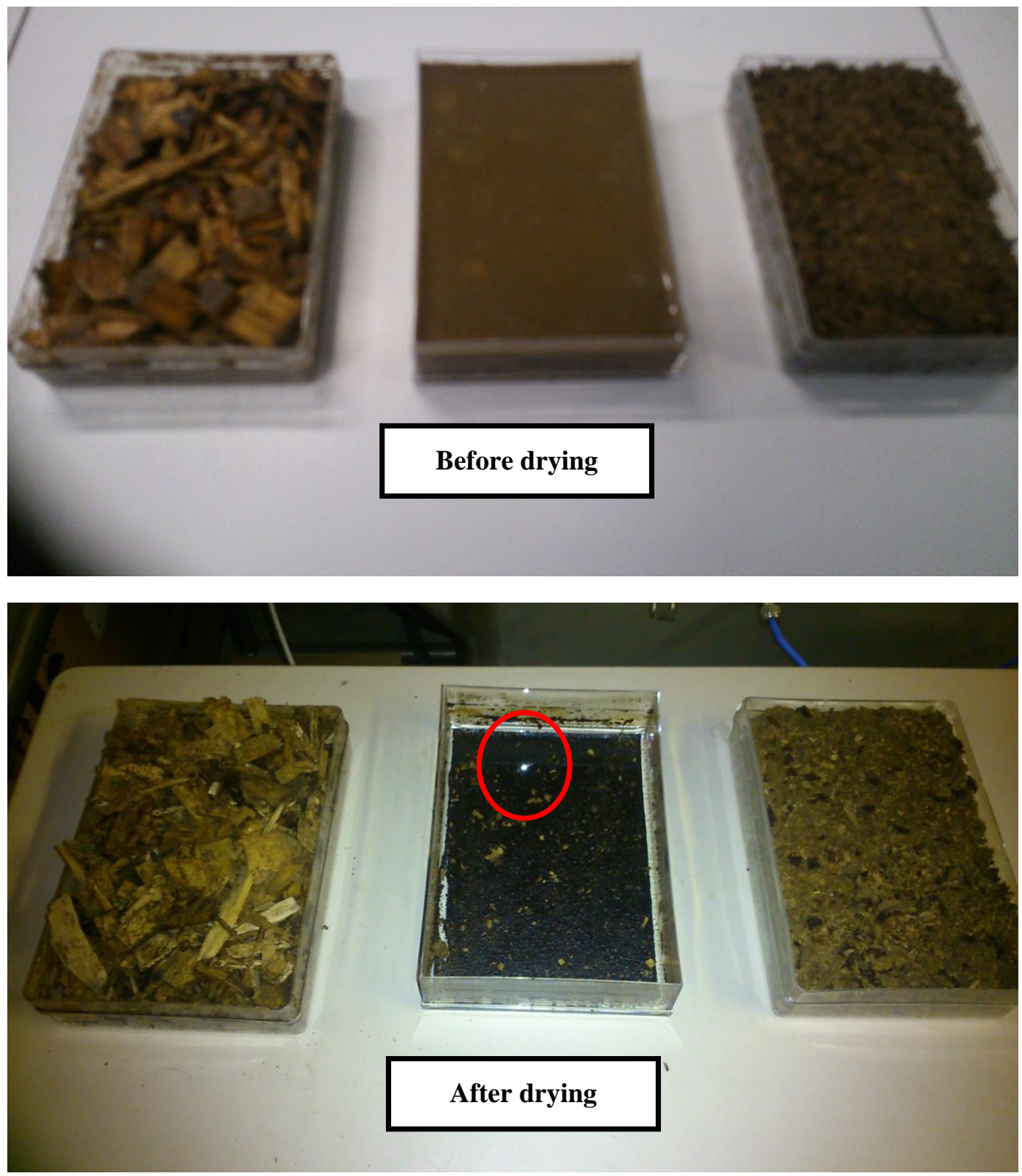

Figure 5. IWC, OMWW, and IS before and after drying.

\subsection{Water Recovery}

Figure 6 shows the ratio of recovered water by the initial water during the drying operation for OMWW, IS, and IWC. The final ratios of condensed water are interesting since they were around $80 \%$ for OMWW and IWC and as high as 95\% for IS. In a context of water shortage, such yields are very promising for further subsequent use.

The impregnation process not only shortened the drying time during the first step, but also increased the contained water recovery ratio by $18 \%$ to $35 \%$ during the whole condensation operation. Moreover, dried IS samples have the shape of bricks (Figure 7) with good mechanical properties on one hand and with increased high heating values (18 MJ/kg) compared to non-impregnated ones $(16.4 \mathrm{MJ} / \mathrm{kg})$ on the other hand. These bricks are homogenous, well-bonded, and can be easily removed from the container, contrarily to the dried OMWW where the oily and plastic phase makes it stick to the box and hard to remove. All these aspects make dried IS easy to handle, transport, and store and, suitable for direct use as bio-fuels or for a densification process by briquetting or pelletizing. 


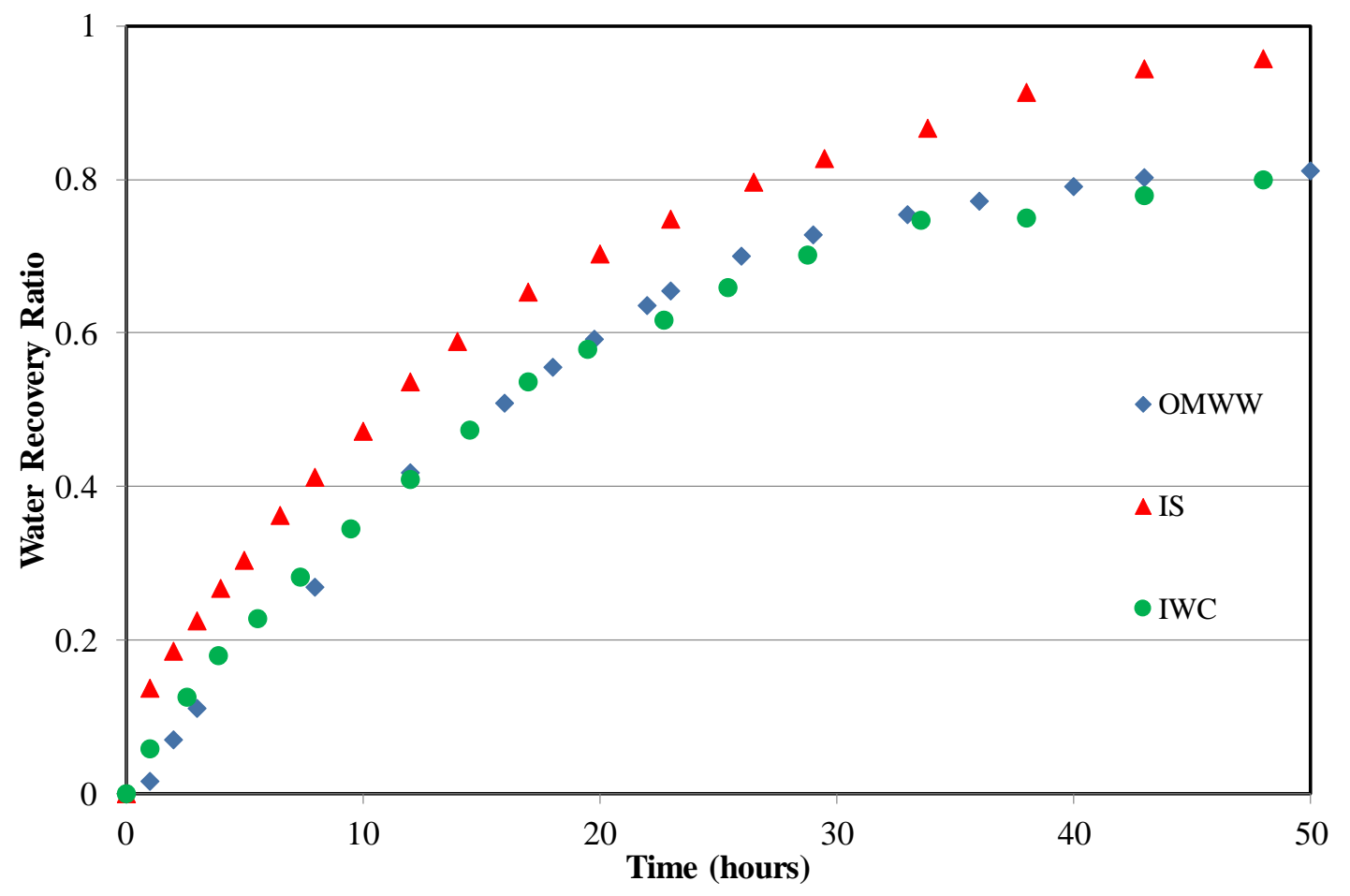

Figure 6. Water recovered ratio during drying for OMWW, IS, and IWC.

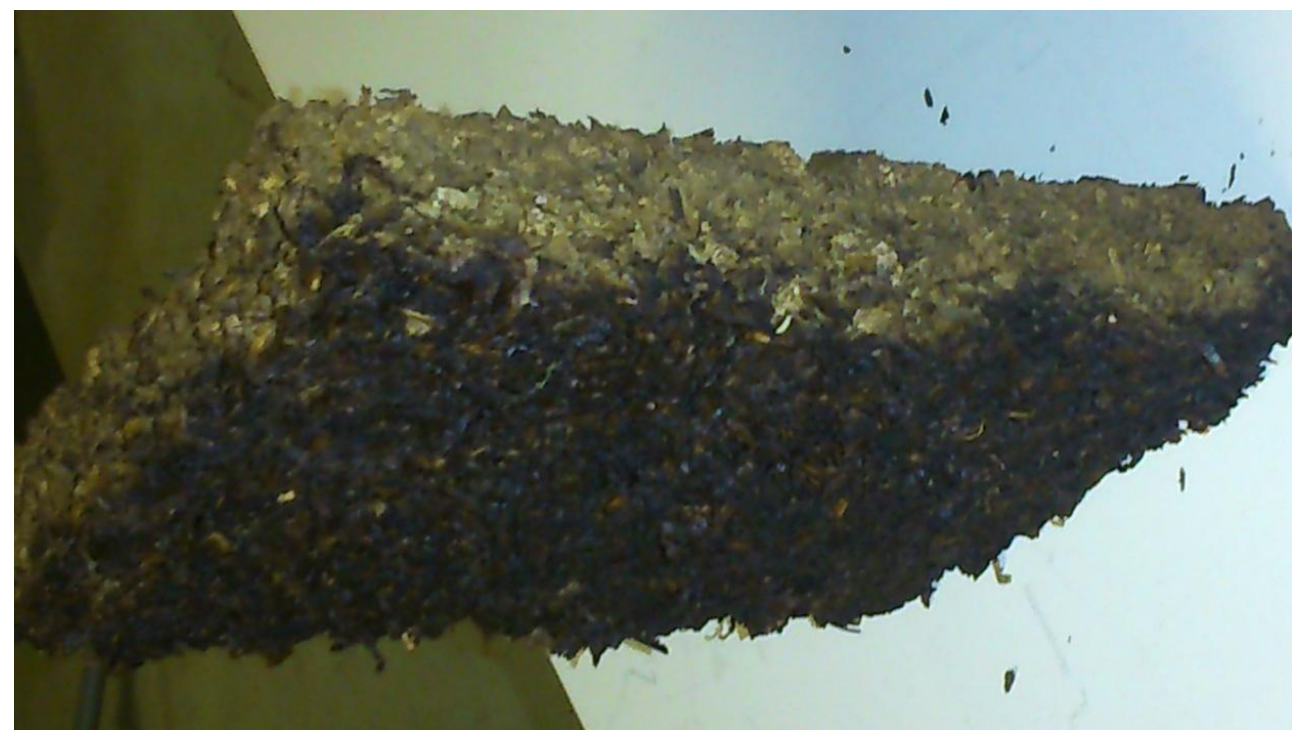

Figure 7. Impregnated sawdust at the end of the drying operation.

\subsection{Recovered Water Characterization}

Figure 8 shows the aspect of recuperated condensed water (right) and of the raw OMWW (left). Despite the clearness of the obtained waters, their characterization is essential to ensure their compliance with water irrigation standards. 


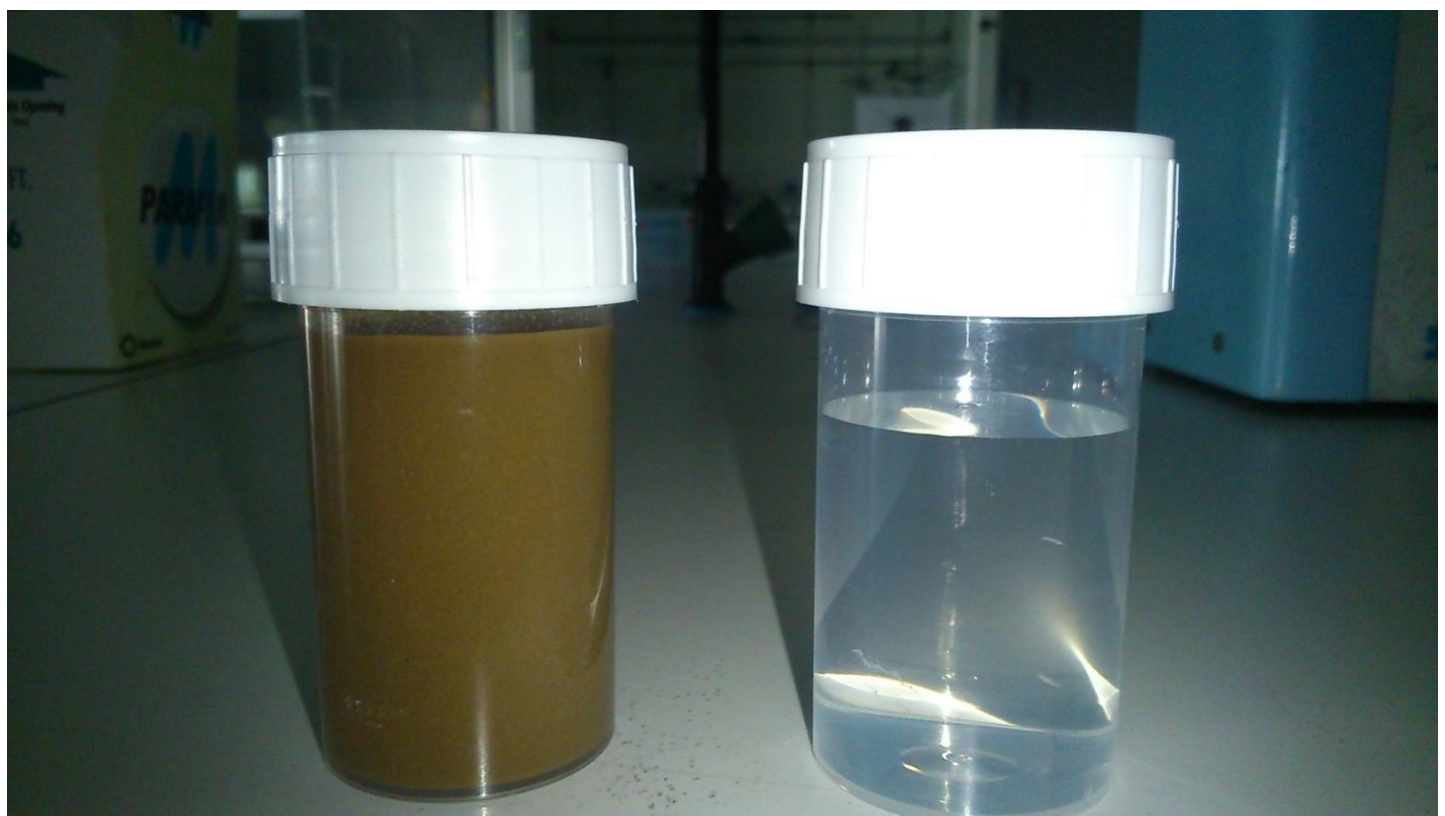

Figure 8. Aspect of OMWW (left) and recovered-condensed water from raw OMWW (right).

As mentioned in Section 2.4, several parameters were measured for this purpose. Table 2 gives these main physico-chemical properties of the raw OMWW and the recovered water from the drying operation of OMWW, IS, IWC, HS, and HWC, in comparison with the Tunisian standard for both discharging in water bodies and reuse in agriculture (norms NT 4106.002, NT 106.003 and decree-law N89-1047 of 28 July 1989).

Table 2. Main parameters of raw OMWW and allowable concentrations (standards).

\begin{tabular}{ccccccccc}
\hline Parameter & $\begin{array}{c}\text { Raw } \\
\text { OMWW }\end{array}$ & OMWW & IS & IWC & HS & HWC & $\begin{array}{c}\text { Discharging } \\
\text { Norm }\end{array}$ & $\begin{array}{c}\text { Reuse in } \\
\text { Agriculture Norm }\end{array}$ \\
\hline $\mathrm{pH}$ & 4.8 & 3.5 & 3.9 & 3.8 & 3.8 & 3.7 & $6.5-8.5$ & $6.5-8.5$ \\
$\mathrm{EC}(\mathrm{mS} / \mathrm{cm})$ & 9.73 & 0.25 & 0.23 & 0.27 & 0.05 & 0.02 & 5.00 & 7.00 \\
$\mathrm{COD}(\mathrm{g} / \mathrm{L})$ & 100.00 & 8.38 & 2.10 & 8.40 & 0.10 & 0.04 & 0.13 & -0.09 \\
$\mathrm{Na}^{+}(\mathrm{mg} / \mathrm{L})$ & 2465.0 & 2.0 & 3.3 & 1.2 & 3.3 & 2.6 & 700 & - \\
$\mathrm{K}^{+}(\mathrm{mg} / \mathrm{L})$ & 5046.5 & 5.0 & 1.9 & 2.0 & 2.1 & 4.5 & 50 & - \\
$\mathrm{Mg}^{2+}(\mathrm{mg} / \mathrm{L})$ & 1462.5 & 0.4 & 1.1 & 0.4 & 0.8 & 1.0 & 300 & - \\
$\mathrm{Ca}^{2+}(\mathrm{mg} / \mathrm{L})$ & 1907.8 & 1.7 & 4.3 & 1.5 & 3.0 & 3.9 & 500 & - \\
$\mathrm{P}_{\text {total }}(\mathrm{mg} / \mathrm{L})$ & 832.1 & 0.7 & 1.6 & 1.4 & 24.8 & 1.9 & 2 & - \\
$\mathrm{NO}_{3}^{-}(\mathrm{mg} / \mathrm{L})$ & 1056.8 & 1.5 & 1.6 & 0.4 & 3.0 & 5.5 & 600 & 700 \\
$\mathrm{Cl}^{-}(\mathrm{mg} / \mathrm{L})$ & 1912.9 & 4.8 & 4.3 & 2.3 & 8.5 & 2.6 & & 2000.0 \\
\hline
\end{tabular}

According to Table 2, all the raw OMWW physico-chemical characteristics were much higher than the discharging and reuse requirements. For instance, the OMMW' COD contents and phosphorus concentrations were about 769- and 416-fold higher than the related fixed maximum concentrations, respectively.

At the same time, the drying operation significantly decreased the $\mathrm{pH}$ of the recovered water solution compared to the raw OMWW (4.77). Indeed, the $\mathrm{pH}$ values of the recovered solutions varied between 3.9 for IS and 3.5 for OMWW. These values are again very low compared to the fixed norms of discharging and reuse (Table 2). However, their adjustment to these norms could be easily performed by filtrating these recovered solutions through low-cost alkaline wastes such as seashell [25] or powdered marble [26]. Furthermore, the drying procedure also significantly decreased the electrical conductivity of the raw OMWW from $9.73 \mathrm{mS} \mathrm{cm}^{-1}$ to about $0.25 \mathrm{mS} \mathrm{cm}^{-1}$ for the recovered waters. This result was expected since waters that were evaporated during convective drying (low-temperature drying) contain very little inorganic ionic compounds. All these values were significantly lower than the fixed 
norm for wastewater discharging in water bodies or reuse in agriculture. The blank tests (HS and HWC) showed a low impact of the sawdust and the wood chips since the related recovered waters had very low EC and COD compared to the same solid matrixes when impregnated with OMWW.

Concerning the COD contents, all the recovered water solutions had low values compared to the raw OMWW $\left(100 \mathrm{~g} \mathrm{~L}^{-1}\right)$. The lowest value $\left(2.1 \mathrm{~g} \mathrm{~L}^{-1}\right)$ was registered for impregnated sawdust (IS). The highest one $\left(8.4 \mathrm{~g} \mathrm{~L}^{-1}\right)$ was observed for IWC and could be imputed to the release of supplementary organic matter from the solid matrix into the impregnating liquid phase. Electrical conductivity, $\mathrm{pH}$, and COD tests were duplicated with recovered waters from different drying experiments. While $\mathrm{pH}$ and EC were close to each other, COD measurements were sensibly different (for example 2.3 and $14.4 \mathrm{~g} \mathrm{~L}^{-1}$ for OMWW). This difference is attributed to the time spent in open air. Indeed, the more the air was evacuated, the more the COD was decreased $\left(2.3 \mathrm{~g} \mathrm{~L}^{-1}\right.$ with $12 \mathrm{~h}$ venting and $14.4 \mathrm{~g} \mathrm{~L}^{-1}$ with no aeration). All the measured COD contents of the recovered waters were higher than the set standards. These values could be significantly decreased through specific treatment (depending on the detailed characterization of the contained dissolved organic matter) and mixing with other waters.

On the other hand, the IC analyses showed that for all the samples, the main anions and cations contents were significantly lower than the fixed norms (Table 2). Moreover, the suggested treatment cited above for the increase of these recovered waters $\mathrm{pH}$ by using low-cost alkaline materials such as powdered marble or seashell, will certainly enrich them with mineral elements such as calcium and magnesium.

Moreover, GC-MS investigations showed that the organic chemicals found came from olive oil, residues, and wood. Indeed, classical fatty acids coming from olive oil such as myristic, palmitic, and stearic acids, as well as tyrosol and vanillin were transferred into the recovered waters. Waters from OMWW and impregnated biomasses also contained short-chain acids such as acetic, malonic, butanoic, fumaric, and succinic, which could explain the difference of COD after sample venting.

Wood chips and sawdust significantly released chemicals like glycerol, beta-alanine, D-glucose, urea, and some short-chain organic acids (D-glyceric, succinic, acetic, etc.)) into waters. These chemicals come from both impregnated biomasses and humidified ones.

Therefore, a tertiary treatment is necessary to adjust the $\mathrm{pH}$ and decrease the COD in order to use these waters in agriculture. A low-cost solution could be the filtration through low-cost materials such as the cited-above raw/modified mineral wastes (seashell or powdered marble) and a proper ventilation to extract organic volatile compounds.

\section{Conclusions}

In this paper, a sustainable strategy for recovery of water from olive mill wastewater (OMWW) is proposed. This strategy includes (i) the impregnation of OMWW on lignocellulosic biomass (oak sawdust, wood chips), (ii) the controlled drying of the impregnation samples in a convective dryer, (iii) the water recovery from the drying operation through condensation process, and (iv) the material recovery of the dried impregnated biomasses for thermochemical conversion process (combustion/pyrolysis for energy/biochar production).

The quality of the recovered water was emphasized in this present work. In particular, different characterization techniques were used in order to assess the potential use of the recovered water in agriculture application. It was observed that the condensate waters are attractive for an agricultural purpose, but they do require an additional treatment to adjust the $\mathrm{pH}$ and to decrease its COD content.

This study performed at laboratory scale is a useful starting point for scaling up and ensuring sustainability.

Author Contributions: Conceptualization, P.D. and M.J.; methodology, P.D., M.-L.G. and S.J.; software, B.K.; validation, P.D., M.J. and S.J.; formal analysis, M.J. B.K. and M.-L.G.; investigation, P.D. and M.-L.G.; resources, P.D. and S.J.; data curation, P.D., M.J. and B.K.; writing—original draft preparation, B.K. and M.J.; writing-review and editing, P.D. and S.J.; visualization, P.D. and M.-L.G.; supervision, P.D., M.J. and S.J.; project administration, M.J.; funding acquisition, P.D., M.J. and S.J. 
Funding: This work was partially funded by FERTICHAR project. FERTICHAR is funded through the ARIMNet2 (2017) Joint Call by the following funding agencies: ANR (France), HAO-DEMETER (Greece), MHESRT (Tunisia), ARIMNet2 (ERA-NET) has received funding from the European Union's Seventh Framework Programme for research, technological development and demonstration under grant agreement no. 618127. The authors gratefully acknowledge the funding agencies for their support. Authors would like also to thank the Region Alsace (now Grand Est) for its financial support concerning the drying unit pilot. This funding was given in the frame of the SEBASTE project $\left(n^{\circ} 131280\right)$.

Conflicts of Interest: The authors declare no conflict of interest.

\section{References}

1. Iglesias, A.; Garrote, L.; Flores, F.; Moneo, M. Challenges to Manage the Risk of Water Scarcity and Climate Change in the Mediterranean. Water Resour. Manag. 2007, 21, 775-788. [CrossRef]

2. Angelakis, A.N.; Marecos Do Monte, M.H.F.; Bontoux, L.; Asano, T. The status of wastewater reuse practice in the Mediterranean basin: Need for guidelines. Water Res. 1999, 33, 2201-2217. [CrossRef]

3. Mizyed, N.R. Challenges to treated wastewater reuse in arid and semi-arid areas. Environ. Sci. Policy 2013, 25, 186-195. [CrossRef]

4. Pedrero, F.; Kalavrouziotis, I.; Alarcón, J.J.; Koukoulakis, P.; Asano, T. Use of treated municipal wastewater in irrigated agriculture-Review of some practices in Spain and Greece. Agric. Water Manag. 2010, 97, 1233-1241. [CrossRef]

5. Khiari, B.; Wakkel, M.; Abdelmoumen, S.; Jeguirim, M. Dynamics and kinetics of cupric ion removal from wastewaters by Tunisian solid crude olive-oilwaste. Materials 2019, 12, 365. [CrossRef]

6. Wakkel, M.; Khiari, B.; Zagrouba, F. Textile wastewater treatment by agro-industrial waste: Equilibrium modelling, thermodynamics and mass transfer mechanisms of cationic dyes adsorption onto low-cost lignocellulosic adsorbent. J. Taiwan Inst. Chem. Eng. 2019, 96, 439-452. [CrossRef]

7. Khan, S.; Cao, Q.; Zheng, Y.M.; Huang, Y.Z.; Zhu, Y.G. Health risks of heavy metals in contaminated soils and food crops irrigated with wastewater in Beijing, China. Environ. Pollut. 2008, 152, 686-692. [CrossRef] [PubMed]

8. Wakkel, M.; Khiari, B. Basic red 2 and methyl violet adsorption by date pits: Adsorbent characterization, optimization by RSM and CCD, equilibrium and kinetic studies. Environ. Sci. Pollut. Res. 2018, 1-19. [CrossRef] [PubMed]

9. Libutti, A.; Gatta, G.; Gagliardi, A.; Vergine, P.; Pollice, A.; Beneduce, L.; Disciglio, G.; Tarantino, E. Agro-industrial wastewater reuse for irrigation of a vegetable crop succession under Mediterranean conditions. Agric. Water Manag. 2018, 196, 1-14. [CrossRef]

10. Marrakchi, F.; Kriaa, K.; Hadrich, B.; Kechaou, N. Experimental investigation of processing parameters and effects of degumming, neutralization and bleaching on lampante virgin olive oil's quality. Food Bioprod. Process. 2015, 94, 124-135. [CrossRef]

11. Souilem, S.; El-Abbassi, A.; Kiai, H.; Hafidi, A.; Sayadi, S.; Galanakis, C.M. Chapter 1-Olive oil production sector: Environmental effects and sustainability challenges. In Olive Mill Waste; Galanakis, C.M., Ed.; Academic Press: Cambridge, MA, USA, 2017; pp. 1-28.

12. Negro, M.J.; Manzanares, P.; Ruiz, E.; Castro, E.; Ballesteros, M. Chapter 3-The biorefinery concept for the industrial valorization of residues from olive oil industry. In Olive Mill Waste; Galanakis, C.M., Ed.; Academic Press: Cambridge, MA, USA, 2017; pp. 57-78.

13. Kapellakis, I.E.; Tzanakakis, V.A.; Angelakis, A.N. Land application-based management of olive mill wastewater. Water 2015, 7, 362-376. [CrossRef]

14. Caputo, A.C.; Scacchia, F.; Pelagagge, P.M. Disposal of by-products in olive oil industry: Waste-to-energy solutions. Appl. Therm. Eng. 2003, 23, 197-214. [CrossRef]

15. Miranda, T.; Esteban, A.; Rojas, S.; Montero, I.; Ruiz, A. Combustion analysis of different olive residues. Int. J. Mol. Sci. 2008, 9, 512-525. [CrossRef] [PubMed]

16. Jeguirim, M.; Chouchène, A.; Réguillon, A.F.; Trouvé, G.; Le Buzit, G. A new valorisation strategy of olive mill wastewater: Impregnation on sawdust and combustion. Resour. Conserv. Recycl. 2012, 59, 4-8. [CrossRef]

17. Kraiem, N.; Jeguirim, M.; Limousy, L.; Lajili, M.; Dorge, S.; Michelin, L.; Said, R. Impregnation of olive mill wastewater on dry biomasses: Impact on chemical properties and combustion performances. Energy 2014, 78, 479-489. [CrossRef] 
18. Haddad, K.; Jeguirim, M.; Jerbi, B.; Chouchene, A.; Dutournié, P.; Thevenin, N.; Ruidavets, L.; Jellali, S.; Limousy, L. Olive Mill Wastewater: From a Pollutant to Green Fuels, Agricultural Water Source and Biofertilizer. ACS Sustain. Chem. Eng. 2017, 5, 8988-8996. [CrossRef]

19. Jeguirim, M.; Dutournié, P.; Zorpas, A.A.; Limousy, L. Olive Mill Wastewater: From a Pollutant to Green Fuels, Agricultural Water Source and Bio-Fertilizer-Part 1. The Drying Kinetics. Energies 2017, 10, 1423.

20. Amos, W.A. Report on Biomass Drying Technology; Technical Report; National Renewable Energy Lab.: Golden, CO, USA, 1999. [CrossRef]

21. Borsato, A.V.; Doni-Filho, L.; Rakocevic, M.; Cocco, L.C.; Paglia, E.C. Chamomile essential oils extracted from flower heads and recovered water during drying process. J. Food Process. Preserv. 2009, 33, 500-512. [CrossRef]

22. Moore, W.A.; Kroner, R.C.; Ruchhoft, C.C. Dichromate Reflux Method for Determination of Oxygen Consumed. Anal. Chem. 1949, 21, 953-957. [CrossRef]

23. Montero, I.; Miranda, T.; Arranz, J.I.; Rojas, C.V. Thin Layer Drying Kinetics of By-Products from Olive Oil Processing. Int. J. Mol. Sci. 2011, 12, 7885-7897. [CrossRef]

24. Khiari, B.; Mihoubi, D.; Mabrouk, S.B.; Sassi, M. Experimental and numerical investigations on water behaviour in a solar tunnel drier. Desalination 2004, 168, 117-124. [CrossRef]

25. Selimi, A.; Nickelson, R. Effects of liming on soil $\mathrm{pH}$ and manganese toxicity in a Goulburn valley pear orchard. Aust. J. Exp. Agric. 1972, 12, 310-314. [CrossRef]

26. Haddad, K.; Jellali, S.; Jaouadi, S.; Benltifa, M.; Mlayah, A.; Hamzaoui, A.H. Raw and treated marble wastes reuse as low cost materials for phosphorus removal from aqueous solutions: Efficiencies and mechanisms. C. R. Chim. 2015, 18, 75-87. [CrossRef]

(C) 2019 by the authors. Licensee MDPI, Basel, Switzerland. This article is an open access article distributed under the terms and conditions of the Creative Commons Attribution (CC BY) license (http://creativecommons.org/licenses/by/4.0/). 